\title{
Professor: protagonista e obstáculo da reforma
}

Olinda Evangelista

Eneida Oto Shiroma

Universidade Federal de Santa Catarina

\section{Resumo}

0 artigo discute a formação docente no contexto da reforma do Estado no Brasil, articulada às recomendações dos organismos internacionais para a Educação no início do século XXI. Para tanto, utiliza-se do conceito de Agenda Globalmente Estruturada para a Educação (AGEE), proposto por Roger Dale. Esse conceito permite pensar sobre tais reformas, apreendendo-as na dinâmica estabelecida entre países centrais e países periféricos no interior da divisão internacional do trabalho. A análise incide sobre três grandes projetos para a Educação na América Latina e Caribe: o Proyecto Regional de Educación para América Latina y el Caribe - PREALC -, patrocinado pela UNESCO; o Plan de Cooperación, resultante das Cumbre lberoamericana de Educación, patrocinadas pela OEl; e os Proyectos hemisféricos en educación, patrocinados pela OEA. Privilegia-se, neste artigo, o modo pelo qual essas organizações procuram construir o professor como protagonista e, ao mesmo tempo, como obstáculo à reforma educacional, desqualificando-o teórica e politicamente. Procura-se evidenciar que, no corpus documental dos organismos indicados, dois conceitos são fundamentais para a compreensão da reforma da formação: profissionalização e gerencialismo. A centralidade atribuída a ambos tem em vista ampliar o controle sobre a categoria do magistério e sua potencial capacidade de opor-se às reformas e ao Estado. Corrobora-se a tese de que a reforma educacional tem pouco a ver com questões propriamente educativas e muito mais com a busca de uma nova governabilidade da Educação pública.

\section{Palavras-chave}

Formação docente - Profissionalização - Gerencialismo - Reforma educacional.
Correspondência:

Eneida Oto Shiroma

Rua das Cerejeiras, n. 127

88040-510 - Florianópolis - SC

e-mail: eneida@ced.ufsc.br 


\section{Teacher: protagonist and obstacle to the reform}

Olinda Evangelista

Eneida Oto Shiroma

Universidade Federal de Santa Catarina

\begin{abstract}
The article discusses teacher education within the context of the reform in the Brazilian State, articulated to the recommendations made by the international bodies for education at the start of the $21^{\text {st }}$ century. For that, it makes use of the concept of Globally Structured Educational Agenda (GSEA) as proposed by Roger Dale. This concept invites us to think about these reforms, understanding them inside the dynamics established between the central economies and the peripheral countries in the international division of labor. The analysis focuses on three large educational projects for education in Latin America and the Caribbean: the Proyecto Regional de Educación para América Latina y el Caribe - PREALC, sponsored by UNESCO, the Plan de Cooperación, which resulted from the Cumbre Iberoamericana de Educación sponsored by $\mathrm{OEI}$ (Organization of Ibero-American States), and the Proyectos hemisféricos en educación sponsored by OAS. In this article we emphasize the way in which these organizations try to build the teacher simultaneously as protagonist and obstacle to the educational reform, discrediting them theoretically and politically. We seek to evince the fact that in the documental corpus of the above-mentioned organizations two concepts are fundamental to understand the reform in teacher education: professionalization, and management culture. The centrality attributed to these two concepts aims at extending the control over the teaching category and its potential to oppose reforms and the State. These conclusions corroborate the thesis that educational reforms have little to do with strictly educational issues, and are more related to the search for a new governability of public education.
\end{abstract}

\section{Keywords}

Teacher education - Professionalization - Management culture Educational reform. 
A discussão em torno da função docente tem sido um dos temas centrais em nossos estudos. Nas pesquisas que vimos realizando, procuramos entender a especificidade do trabalho do professor, particularmente na sociedade brasileira contemporânea. Certamente essa abordagem não se pode desvincular das linhas políticas que vêm sendo implementadas na América Latina e Caribe e em nível global. Para apreender a relação local-regional-global, temos trabalhado com o instigante conceito de "agenda globalmente estruturada para a educação”, proposto por Roger Dale (2001). Esse conceito nos permite discutir tanto a posição do Brasil no que tange às políticas internacionais em vigência, quanto a da América Latina e Caribe e a dos países hegemônicos. Na esteira de Dale, podemos pensar que se não se pode homogeneizar os países ou regiões, posto que cada um ocupa uma posição distinta na divisão internacional do trabalho, também não se pode secundarizar o fato de que há lineamentos originários das grandes agências multilaterais, articulados aos interesses dos países capitalistas hegemônicos, que têm em vista produzir, nas diferentes regiões do mundo, um professor com inúmeros elementos em comum, instrumentalizado com objetivos assemelhados.

Nessa linha de argumentação, defendemos a idéia de que o professor está sendo constituído como obstáculo à reforma educacional e, mais, à reforma do Estado. Intelectuais ligados ao Programa de Promoção da Reforma Educativa na América Latina e Caribe - PREALC - afirmaram que "o maior obstáculo para a implementação das reformas educativas é o professor" (Puryear, 2003). Um tal raciocínio deve-se, provavelmente, ao reconhecimento do fato de que os professores compõem a maior e mais organizada categoria de funcionários públicos na maioria dos países (Delors, 1998; Tedesco, 1998) e sua ação pode, em tese, configurar-se como obstáculo às propostas de reforma seja por apresentarem uma oposição crítica ou, mesmo, por não entenderem de que trata a reforma.

Se isso é verdade, há sentido no uso que fazemos de uma outra idéia de Roger Dale (Stoer,
2000), a de que há uma retórica no campo hegemônico que produz uma compreensão do sujeito como homem obstáculo. A fecundidade dessa metáfora levou-nos a usá-la em um outro contexto, mas perfeitamente compatível com seu sentido original. Nos discursos divulgados pelas agências multilaterais, o docente está sendo construído como professor obstáculo, como se verifica na passagem seguinte: "o professor sabetudo deverá dar lugar a um professor que se propõe aprender, e o professor obstáculo tornar-seá um professor agente da inovação" (Costa, 2005). 0 que nos interessa nesse trabalho é procurar entender por que o professor é construído como obstáculo e qual a força a ele atribuída de modo a pô-lo, a um só tempo, na condição de causa e solução dos problemas educacionais. Cientes de que o campo docente não comporta uma ação dessa natureza e, ademais, de que a escola não é território destinado à solução de problemas de ordem econômica e social, perguntamos: por que a política em curso - nacional e internacional - insiste nessa falácia?

É possivel concordar com o fato de que há uma capacidade de organização do magistério público que parece causar temor aos órgãos governamentais e internacionais, razão pela qual está em causa sua adesão ao projeto reformador. Nesse intento, destaca-se a política de profissionalização, não por seu potencial de elevar a qualificação dos professores, mas pela possibilidade objetiva de instituir novas formas de controle sobre os docentes (Ozga, 2001). Essa hipótese encontra evidências no alto grau de homogeneidade das reformas e das prioridades em torno da eficiência, profissionalização e gestão em diversas partes do globo. Não há dúvidas sobre a existência de projetos que disputam a definição das prioridades para a Educação, das diretrizes para a formação docente, do modelo de gestão da escola, da formação de gestores, entre outros campos importantes. No entanto, afinal, quem está na disputa e qual sua motivação para tal? A resposta à última permite responder à primeira questão. 0 litígio se põe pelo controle do processo de formação das novas gerações 
de trabalhadores. Está em questão manter o estoque da força de trabalho nacional, o processo de reprodução da capacidade de trabalho e, ao mesmo tempo, a gestão da pobreza. Se essas são as motivações objetivas para a luta pelo sentido teleológico da Educação, os projetos em disputa não são difíceis de serem compreendidos, pois se trata da recomposição da hegemonia capitalista ou, como sugere Oliveira (2000), das necessidades de recomposição das condições gerais da produção capitalista e da perspectiva histórica daqueles que se lhe opõem.

\section{Uma agenda globalmente estruturada para a Educação}

A tese da "agenda globalmente estruturada para a educação" (AGEE) busca estabelecer mais claramente as ligações existentes entre as mudanças na política e prática educativas e as da economia mundial. Roger Dale (2001), proponente da tese, entende a globalização como um conjunto de dispositivos político-econômicos para a organização da economia global, conduzido pela necessidade de manter o sistema capitalista em detrimento de qualquer outro conjunto de valores. A adesão aos seus princípios é veiculada por meio de pressão econômica com base na qual as forças econômicas operam transnacionalmente. A conformação dessa espécie de governação supranacional estende-se por três conjuntos de atividades: econômicas (caracterizadas pelo hiperliberalismo), políticas (visando a governação sem governo) e culturais (marcadas pela mercadorização e consumismo). A governança, entendida como a capacidade de implementar de forma eficiente as políticas públicas, tornou-se objetivo-chave de organismos internacionais (0I), como o Banco Mundial, por exemplo. Nesse processo, de seu ponto de vista, os três grandes blocos de poder - Europa, América do Norte e Ásia - competem para manter e fazer avançar suas estratégias de acumulação de capital. A globalização não representaria, pois, a hegemonia de uma nação, a americanização do planeta, mas de um sistema - o capitalista - que triunfou.

Não havendo dúvidas sobre as forças em presença e sobre o coração da disputa, é necessário discutir acerca das idéias-força que compõem o ideário da AGEE. Podemos elencar as noções de provisão, financiamento, avaliação, regulação, gestão, controle e desresponsabilização do Estado, seja pela descentralização da execução das políticas, seja pela determinação de seus compromissos por agenda definida pela economia política global. Considera-se importante refletir sobre a problemática do Estado nesse movimento, posto que, não sendo o único sujeito instituinte do político (Bruno, 2002), é, contudo, necessário como mediador dessas relações. Talvez por esse caminho possamos compreender a imposição internacional para sua reforma.

No bojo da denominada modernização do Estado, agências internacionais, como se sabe, propõem a adoção da administração gerencial tanto para racionalizar o gasto público quanto para administrar professores. Na mesma linha, Gandini e Riscal (2002) argumentam que a reforma do Estado foi induzida por fatores exógenos. o Consenso de Washington (1989), entre outros acontecimentos, impôs a regulamentação do campo social de acordo com a nova ordem econômica, ademais de pretender operar mudanças conceituais, canalizando as aspirações sociais e a ação comunitária por meio de projetos que não permitissem a ultrapassagem em relação às metas estabelecidas. No horizonte, está a problemática da governabilidade, razão pela qual o Estado busca legitimação e coesão social, difíceis dada a política que desenvolve de supressão de benefícios sociais historicamente conquistados, em particular no Brasil.

Defendendo-se a idéia de Estado mínimo, ficou, entretanto, evidenciado o seu recuo não propriamente no que respeita à definição das políticas públicas, mas no financiamento das políticas sociais, no estímulo à privatização da educação, saúde, previdência, habitação, saneamento e na transferência da sua responsabilidade de provedor para a sociedade civil, procurando envolver movimentos sociais, organizações não governamentais (ONGs) e sindicatos, catalisando a capacidade gerencial da esfera social, sob a forma de 
parcerias entre outras. De outro lado, à autonomia reiterada no discurso, correspondem a descentralização das questões operacionais e a centralização das questões estratégicas.

A reforma do Estado seria uma resposta a problemas como o fracasso, a ineficiência, a precariedade, a negligência, entre outros, que colocavam em xeque sua capacidade de governar. Procurava-se, pois, testar sua capacidade racionalizadora (Gandini; Riscal, 2002). A relação entre essa reforma e os organismos internacionais não é tão simples de entender. Seu papel relaciona-se diretamente à idéia de governação global. Para Dale (2001), "se um Estadonação específico não é capaz de implementar as políticas adequadas [...] as estruturas da sociedade mundial providenciarão a respectiva ajuda" (p. 163) - financiarão, monitorarão e prescreverão os caminhos que tornarão mais eficiente o desempenho da máquina governamental. Tal estratégia recebe o nome de "administração gerencial de resultados" (CLAD, 1998), por oposição à administração burocrática, e se refere à capacidade de gerenciar a esfera social, os conflitos e as desigualdades sociais, ademais da capacidade de ser um eficiente gerenciador da receita tributária. 0 documento Global knowledge for local solutions (s.d.), do Banco Mundial, ilustra o que acima afirmamos: considera filantropia internacional a proposta de transferência de sua tecnologia de fazer reformas.

\section{Três projetos estratégicos de formação docente}

A filantropia internacional na América Latina e Caribe pode ser percebida em três dos grandes projetos em andamento. 0 primeiro deles, Proyecto Regional de Educación para América Latina y el Caribe - PREALC -, é patrocinado pela UNESCO e está previsto para encerrar-se em 2017'. 0 segundo, Plan de Cooperación - PC -, resulta do Cumbre Iberoamericana de Educación e da Conferencia Iberoamericana de Educación e é patrocinado pela Organización de los Estados Iberoamericanos para la Educación, la Ciencia y la Cultura - OEl -, tendo o apoio da OCDE que, iniciado em 2000, prevê seu encerramento em 2010. 0 terceiro, Proyectos hemisféricos en educación - PHE -, articula-se ao Cumbre de las Américas, é patrocinado pela Organização dos Estados Americanos - OEA - e conta com o apoio da UNESCO, da UNICEF, do Convênio Andrés Bello, do BIRD, do BM e da OEl (Torres, 2004)², tendo iniciado em 1994 e com previsão de encerramento para 2010.

É possível verificar que as agências se entrelaçam no financiamento simultâneo aos três projetos. A sua parceria também é perceptível nos conteúdos de cada projeto, embora, como veremos, haja diferenças em alguns pontos. No caso dos conceitos operativos comuns e no que se refere ao interesse deste trabalho, as duas diretrizes que selecionamos para estudo - profissionalização e gestão - aparecem em todos os projetos. Tais diretrizes articulam-se a uma análise de conjuntura que dá a globalização como inexorável e desejável. Tratar-se-ia apenas de corrigir suas disfunções como, por exemplo, o desemprego e a pobreza. Desse modo, o problema do desenvolvimento humano é central e nele a educação desponta como a principal protagonista, particularmente sob a forma de educação ao longo da vida (PREALC) ou de formação contínua (PC, PHE). Nesse âmbito, a profissionalização docente assume grande importância ao lado da gestão. Entretanto, o foco para o qual essas ações estão dirigidas não é o mesmo do ponto de vista terminológico e conceitual. Para o PREALC, o que está em jogo é a governabilidade dos Estados e do planeta. A política educacional é tomada como solução para assegurar o acesso de todos à sociedade do conhecimento e da infor-

1. 0 PREALC seguiu-se ao PROMEDLAC, que começou em 1980 e encerrou-se em 2000, data de início do PREALC. Ambos estão articulados às Conferências de Educação para Todos, realizadas em Jontiem (1990) e Dakar (2000).

2. Além dos três referidos, circulam no mundo os seguintes projetos: Educação para Todos - EPT (1990-2000-2015), patrocinado pelas OI UNESCO, UNICEF, PNUD, BM; Objetivos de Desenvolvimento do MilênioODM (2000-2015), patrocinado pelas OI, ONU, OCDE, FMI, BM; Plano de Ação Iberoamericano pela Infância - PAll (2001-2010), patrocinado pelas OI, OEI, CEPAL, UNICEF; e a Iniciativa Acelerada de Educação para Todos - EFA Fast Track (2002-2015), patrocinado pelo BM. 
mação, aparentemente tomadas como sinônimos. Para o PHE, trata-se da administração da pobreza, e também aqui a Educação é chamada a atuar, mas de modo descentralizado e autônomo. Isto é, a pobreza é um problema do povo e o este deve resolvê-lo por conta própria. 0 papel dos organismos internacionais e do Estado está mais na indução e articulação de políticas do que no seu financiamento e na sua execução. Para o PC, o que está em causa é a reconversão profissional tanto do trabalhador quanto do professor. Tal reconversão lastreiase no conceito de competências como novo paradigma formativo.

A preocupação dos 01 com a formação docente e a gestão chega ao paroxismo quando, no 111 Cumbre de las Américas, no Québec, George Bush anunciou a criação de Centros Hemisféricos para a Excelência Docente para "servir a los países del Caribe, los países de zona Andina y de los de Centroamerica” com o objetivo de "mejorar la calidad de los maestros y administradores escolares" (CIE, 2003). Atualmente treze países encaminham essa diretriz, financiada pela USAID, para atingir 15.000 professores.

Nesses projetos, também se difunde uma perversa imagem de professor: corporativista; avesso às mudanças; acomodado pela rigidez da estrutura de cargos e salários da carreira docente; desmotivado, pois não há diferenciação por mérito, por desempenho, ou seja, como obstáculo às reformas. As iniciativas dos professores contrárias a essa política, suas resistências, suas lutas contra as reformas, foram constatadas em recentes pesquisas (Oliveira, 2003). Todavia, seu posicionamento parece ter recrudescido a posição de 01 que, em conjunção com Estados nacionais, procuram enfraquecer material e simbolicamente os professores para atingi-los em seu trabalho e em sua formação.

Para Krawczyk (2002), a reforma educacional tem pouco a ver com questões propriamente educativas e muito mais com a busca de uma nova governabilidade da educação pública. A governabilidade, na área educacional, constrói-se, então, por duas vias: profissionalização docente e implementação do gerencialismo nas escolas (Clark; Newmann, 1997; Llavador, 2003; Laval, 2004).

No caso brasileiro, as recentes Diretrizes Curriculares Nacionais para o Curso de Pedagogia, Resolução 1/06 do Conselho Nacional de Educação - CNE - (Brasil, 2006), explicitam, simultaneamente, uma restrição nos conteúdos da formação docente, centrados numa perspectiva de saber instrumental, e um alargamento das funções docentes incorporando, por exemplo, tarefas de gestão e outras não diretamente ligadas ao ensino (Evangelista, 2006). Manifesta-se, aqui, a preocupação com a eficiência e a eficácia do trabalho docente, inseridas numa lógica racionalizadora, técnica, pragmática, que encontra na defesa abstrata do uso das tecnologias da informação e comunicação sua expressão mais acabada. Assinale-se que a Resolução 1/06 não faz uso do termo professor, aparecendo fortemente a idéia de docência. Em outras palavras, estabelece a primazia da docência como ação em detrimento do professor como sujeito.

\section{Criando obstáculos: transformar os professores numa corporação atrasada}

Conquanto os professores não participem como interlocutores legítimos da definição de diretrizes educativas, são - junto com a escola - alvo preferencial de desqualificação política e profissional, especialmente nos documentos do Banco Mundial. Pelo menos dois tipos de argumentos sustentam tal investida. De um lado, argumenta-se que o professor é corporativista, obsessivo por reajustes, descomprometido com a educação dos pobres, um sujeito político do contra. De outro, que é incapaz teórico-metodologicamente, incompetente, responsável pelas falhas na aprendizagem dos alunos, logo - em última instância - por seu desemprego.

No primeiro caso, o "BM propõe alternativas para impedir que o sistema de ensino fique subjugado à corporação dos professores" (Leher; Barreto, 2003, p. 49). A construção do professor 
como oponente tem alguma base objetiva, pois, ademais de constituírem numerosa categoria de funcionários públicos, em muitos países suas associações estão articuladas aos partidos trabalhistas. A essa aproximação - com relativo poder de irrupção social e potencial para a produção de conflitos -, somam-se a organização sindical e o apoio de congressistas e líderes políticos.

Do ponto de vista dessas agências e do de muitos Estados, os sindicatos resistentes deveriam ser cooptados para não serem impeditivos das reformas. Desse modo, não apenas o professor é objeto da política, mas também os sindicatos o são, posto que, individual ou sindicalmente pensado, o docente é apreendido como uma questão de Estado.

Ao lado da construção da menoridade política do professor, encontramos a segunda estratégia, uma outra forma de desqualificação, a relativa ao seu que fazer profissional. Nesse aspecto, o professor vem sendo atingido por todos os flancos: está na profissão porque não foi aceito em carreiras de maior prestígio; é incapaz para outras funções e a docência foi o que lhe restou; acomodou-se na carreira porque não há incentivos para desempenhos diferentes; não se preocupa com a qualidade do que faz porque seu salário é irrisório. Essas e muitas outras imagens denegatórias justificam uma ação dura sobre os docentes e oferecem o mote para a mobilização de pais e comunidade na tarefa de "incentivar" o professor a dedicar-se à escola e à docência. Resultado: sustenta-se o recuo do Estado nas tarefas relativas ao financiamento público da escola e põe-se no encalço dos professores "boa-vida" uma comunidade que aposta na boa qualidade da escola, concretizada na possibilidade efetiva de assegurar um trabalho ao sol aos seus filhos. Concluímos dizendo que se o professor não era um obstáculo, certamente está sendo construído como tal.

\section{Diretrizes para a (con)formação docente}

Seria ingênuo acreditarmos que a desqualificação da imagem docente seria suficien- te para implementar as reformas neoliberais na Educação. Seria também ingênuo acreditar que é a isso a que se dedicam as agências internacionais, ainda quando em seus documentos essa atuação apareça de modo altamente enfático. As providências concretas para o exercício do controle político-ideológico sobre o magistério envolvem sua formação e sua atuação profissional. Ou seja, a reforma dos anos de 1990, e seu prosseguimento no novo século, atingiu todas as esferas da docência: currículo, livro didático, formação inicial e contínua, carreira, certificação, lócus de formação, uso das tecnologias da informação e comunicação, avaliação e gestão.

Essas políticas vêm conduzindo à intensificação do trabalho docente e, segundo Oliveira (2004), à sua precarização. Os sintomas do sobretrabalho docente podem ser verificados numa longa lista de situações que prenunciam o alargamento das funções docentes: atender mais alunos na mesma classe, por vezes com necessidades especiais; exercer funções de psicólogo, assistente social e enfermeiro; participar nos mutirões escolares; participação em atividades com pais; atuar na elaboração do projeto político-pedagógico da escola; procurar controlar as situações de violência escolar; educar para o empreendedorismo, a paz e a diversidade; envolver-se na elaboração de estratégias para captação de recursos para a escola.

Os impactos dessa sobrecarga de trabalho produzem efeitos visíveis na saúde física e mental do trabalhador da Educação. Assolado por cobranças de produtividade, eficiência, empreendedorismo, criatividade, compromisso com a escola, o professor é obrigado a desenvolver um senso de sobrevivência que, não raro, o transforma em um sujeito competitivo que investe suas energias na tentativa de superar a solidão, a culpa, o fracasso, a impotência, a incompetência, as incertezas. Nessa seara, a lógica da produtividade encontra respaldo dando lugar à idéia de que os bons resultados escolares independem da qualidade da formação e dos salários do professores da Educação Básica. 


\section{Gestão de que e para quem?}

Como assinalado, um dos pilares de sustentação da conformação do professor é a gestão. Esta deve ser pensada em termos amplos, pois se refere mais ao espírito que deve presidir as atividades escolares e à sua extensão a todos os sujeitos na escola do que à figura do diretor propriamente, denominado gestor escolar. Certamente, o diretor é fundamental, tanto que foi redimensionado como gerente (Oliveira, 2002) e líder (Shiroma, 2006), responsável por capitanear as mudanças, acompanhar e monitorar sua implantação.

A gestão assume, pois, centralidade na política e administrar eficientemente a escola e os docentes coloca-se como estratégia para a gestão do trabalho, da pobreza (Oliveira, 2000; Shiroma; Evangelista, 2005) e essencial para fomentar uma nova forma de regulação social adequada à ordem econômica globalizada (Dale; Robertson, 2001). Desse modo, construir consensos em torno da centralidade da Educação é fundamental e o empenho justifica-se pela nobreza de sua finalidade, a educação para todos. Empresários e Estado defendem escola pública para todos, para o povo, em especial para os pobres, para os futuros trabalhadores, para os consumidores e para os sobrantes. Importa realçar que educação para todos não significa educação pela qual todos aprenderiam. Contrariamente, significa que todos deveriam passar alguns anos da sua vida na escola, passíveis de controle social, inculcação ideológica e alguma formação geral para aquisição de competências para o trabalho.

A idéia de que a educação funciona como varinha mágica da economia esteve presente na Teoria do Capital Humano que pretendia explicar as desigualdades entre os países desenvolvidos e subdesenvolvidos pela centralidade que cada um atribuía à educação, ao fator humano (Schultz, 1971). Nos dias que correm, a tese reaparece atualizada. A educação para todos é fundamental para o avanço dos países, mas com ela o Estado não deve gastar muito. É preciso difundir uma concepção de gestão que convença a escola e seus profissionais de que eficiência, eficácia e produtividade são valores necessários à qualidade de seu trabalho, mas sem que isso implique em aumento no quantum destinado ao financiamento da Educação.

As relações entre a reforma da formação docente e a do Estado evidenciam a incorporação do léxico e da lógica gerencial na política educacional, bem como seu impacto nas práticas e relações de trabalho nas escolas e na formação de novas subjetividades (Ball, 2002; Lavvador, 2003). Escolas eficazes são aquelas que fazem mais com menos, que gerem melhor seus recursos, que arrecadam de outras fontes, não dependem do Estado, constroem sua "autonomia" financeira ou cobram mensalidades, fazem parcerias com empresas ou convocam a comunidade escolar a desenvolver iniciativas que permitam arrecadar recursos para realizar seus projetos. 0 que se pretende com isso? Modificar paulatinamente a escola e adequá-la ao orçamento possível, seja ele oriundo do Estado ou de formas particulares de captação de recursos.

Como no setor produtivo, pode-se entender a preocupação com a repetência como produção de desperdício e demanda de retrabalho, pois, na perspectiva gerencial, isso é perda e precisa ser eliminada. Assim, a política de classes de aceleração e de inclusão pode ser vista de outro modo, não apenas como justiça social, direito do aluno, mas como possibilidade objetiva de ter mais estudantes na escola, de ser útil como fator de cálculo dos recursos a serem recebidos pelo financiamento embasado no custo-aluno, visando otimizar o recurso professor.

São vários os documentos que insistem na redução do custo-professor, inclusive hierarquizando iniciativas e medidas que poderiam melhorar a qualidade do ensino na perspectiva das agências internacionais. 0 salário do professor é apontado como não tendo repercussão significativa na melhora da aprendizagem, portanto não precisaria ser priorizado nas reformas, pelo contrário, sua redução foi cogitada, embora tenha sido reconhecido que haveria forte resistência a medidas dessa natureza. A UNICEF, por exemplo, recomenda contratar professores baratos 
(Buckland, 2000), supondo, talvez, que seja mais viável do que rebaixar os salários dos que já estão na ativa. Já o BM (2000) sugere oferecer gratificações por desempenho, introduzindo um sistema de salários diferentes segundo a produtividade de cada professor, produtividade essa baseada nos escores alcançados em termos de rendimento do alunado.

0 discurso gerencial incorporado pelos educadores não é apenas repetição de slogans, mas a evidência de ideologias em disputa. Sua assimilação colabora na produção e reprodução de uma dada concepção de mundo, define prioridades e modos de agir. De fato, a primeira atitude de um governo que quer iniciar uma reforma é impelir à substituição de discursos.

\section{O novo docente: contra o professor obstáculo?}

As questões que levantamos neste texto, longe de encerrarem as discussões, abrem um horizonte de novas indagações. A atuação docente ou a docência de fato é objeto de inúmeras preocupações por parte do Estado e de Organismos Internacionais. Desse ponto de vista, a idéia de professor obstáculo encontra-se referida nas possibilidades objetivas que têm de exercer algum tipo de resistência à implementação da reforma. Não é por outro motivo que essas forças políticas derramam sobre ele diversificadas estratégias de (con)formação, tanto pela via de sua capacitação, quanto de definição de sua atuação profissional. Algumas características são importantes: capacidade de adaptação; rapidez nas respostas e solução de problemas; flexibilidade na gestão dos problemas cotidianos; habilidade em responder às demandas de pais, alunos e gestores. Talvez pudéssemos radicalizar esse raciocínio afirmando que o professor desejado pelos reformadores admitiria ser controlado e perder sua autonomia no que toca aos objetivos e sentido de sua ação. Contudo, há aqui uma contradição, pois se pretende um professor profissional numa escola pensada como mais um lugar de educação. Sem dúvida, a escola também passa por transformações, pois todo lugar é considerado lugar de aprendizagem. De outro lado, novos parceiros são chamados para a tarefa de educar e se definem não pela identidade ou pertencimento a um corpo profissional, mas pelo seu interesse e dedicação declarados, como é o caso dos "amigos da escola".

Resulta desse processo a desarticulação da categoria docente, dificultando a representação e reivindicações coletivas. Em outras palavras, a subjetividade decorrente dessas mudanças é híbrida, posto que não é definida por uma identidade. Segundo Lavvador (2003), o professor desenvolve uma subjetividade branda que atende perfeitamente à nova lógica do mercado na medida em que a uma subjetividade branda corresponde um profissional brando. Afirma o autor que os sujeitos docentes são produzidos mediante vários dispositivos, entre os quais se encontram as formas de organização e gestão de suas instituições. Podemos pensar, então, que o controle do docente não conta, necessariamente, com sua adesão ativa à reforma, mas procura ser assegurado por agências internacionais e Estado, por regulação ou administração, pelo novo gerencialismo escolar (Shiroma, 2006).

0 esforço dos interesses dominantes em solapar o professor obstáculo nem sempre dá resultados positivos. Obviamente, não se evoca aqui o professor "perdido", no entanto, é possível entrar na luta contra essa lógica que se está implantando nas escolas. Há um professor que não quer morrer. E como proceder? 0 desafio é sermos capazes de criar a capacidade coletiva de nossa constituição como sujeitos históricos, capazes de apropriar-nos da dimensão pública da escola e do conhecimento como direito social, capazes de lutarmos pela socialização dos bens culturais e materiais. É necessário que nós, professores, rejeitemos o projeto social excludente em andamento que parece eclipsado pelo brilho envolvente do lema "Educação para Todos". Arriscamo-nos a dizer que preferimos ser, concretamente, professores obstáculos. 


\section{Referências bibliográficas}

BALL, S. J. Reformar escolas/reformar professores e os terrores da performatividade. Revista Portuguesa de Educação, Portugal, n. 15, v. 2, p. 3-23, 2002.

BANCO MUNDIAL. Global knowledge for local solutions. Disponível em <http://www.gdnet.org/subpages/ projects_underreform.html>. (s.d.) Acesso em: 10 maio 2005.

BARRETO, R. G.; LEHER, R. Trabalho docente e as reformas neoliberais. In: OLIVEIRA, D. A. (Org.). Reformas educacionais na América Latina e os trabalhadores docentes. Belo Horizonte: Autêntica, 2003. p. 39-60.

BRASIL/CNE/CP. Resolução n. 1/2006. Institui Diretrizes Curriculares Nacionais para o Curso de Pedagogia, licenciatura. Brasília. Disponível em: <http://portal.mec.gov.br/pdf>. Acesso em 03 maio 2006.

BRUNO, L. Gestão da educação: onde procurar o democrático? In: OLIVEIRA, D. A.; ROSAR, M. de F. F. (Orgs.). Política e gestão da educação. Belo Horizonte: Autêntica, 2002. p. 17-38.

BUCKLAND, P. Making quality basic education affordable: what have we learned? Unicef-PD-ED. Disponível em: <www.unicef.org> . Acesso em: 28 set. 2000.

CENTRO LATINO-AMERICANO DE ADMINISTRAÇÃO PARA O DESENVOLVIMENTO - CLAD. Uma nova gestão para a América Latina. 1998. Disponivel em: <http://www.clad.org.ve/fulltext/ngppor.pdf>. Acesso em: 13 jun. 2004.

CIE. Comisión Interamericana de Educación. Informe final de la primera sesión oficial de la Comisión Interamericana de Educación. México, agosto de 2003. Disponível em: <www.oea.org>. Acesso em: 02 maio 2005.

CLARKE, J.; NEWMAN, J. The managerial state. London: Sage Publications, 1997.

COSTA, F. A. e-Educação: 0 que tem o sector da educação a ganhar com o desenvolvimento da Sociedade da Informação? Lisboa/ PT: Universidade de Lisboa. Semana n. 735 de 25 a 31 de março de 2005. Fundação Calouste Goubekian. Disponível em: $<$ http://www.alentejodigital.pt/rosadopereira/e-Educacao/Fernando_Albuquerque_Costa_e-Educao.pdf $>$. Acesso em: 03 jul. 2005.

DALE, R. Globalização e educação: demonstrando a existência de uma "cultura educacional mundial comum" ou localizando uma "agenda globalmente estruturada para a educação"? Educação, Sociedade \& Culturas, Porto, n.16, p. 133-169, 2001.

DELORS, J. Educação: um tesouro a descobrir. Relatório para a Unesco da Comissão internacional sobre Educação para o século XXI. São Paulo: Cortez/ Brasília: MEC/UNESCO, 1998.

EVANGELISTA, 0. Curso de Pedagogia: hegemonia da docência. Projeto de pesquisa-2006-2007. EED/CED/UFSC, Florianópolis, 2006.

GANDINI, R.; RISCAL, S. A gestão da educação como setor público não-estatal e a transição para o Estado fiscal no Brasil. In: OLIVEIRA, D. A.; ROSAR, M. de F. F. (Orgs.). Política e gestão da educação. Belo Horizonte: Autêntica, 2002. p. 39-58.

KRAWCZYK, N. R. Em busca de uma nova governabilidade na educação. In: OLIVEIRA, D. A.; ROSAR, M. de F. F. (Orgs.). Política e gestão da educação. Belo Horizonte: Autêntica, 2002. p. 59-72.

LAVAL, C. A escola não é uma empresa: 0 ataque neoliberal ao ensino público. Londrina: Planta, 2004.

LLAVADOR, F. B. Organización postfordista y régimen de producción de los nuevos sujetos docentes. In: FERREIRA, N. S. C. (Org.). A gestão da educação na sociedade mundializada: por uma nova cidadania. Rio de Janeiro: DP\&A, 2003. p. 101-125.

OEA. Mandatos Cumbre. México, 2004. Disponível em: <www.oea.org>. Acesso em: 02 maio 2005.

Relatório anual do Secretário-geral à Assembléia Geral. Washington, D.C., maio de 2004. Disponível em: <www.oea.org >. Acesso em: 02 maio 2005. 
Tercera reunión de ministros de educación. Los proyectos hemisféricos en educación. Matriz de aportaciones de organismos internacionales. México, Agosto de 2003. Disponível em: <www.oea.org>. Acesso em: 02 maio 2005.

OEI. XIII Conferencia Iberoamericana de Educación. Plan de Cooperación. Renovación de ideas y formulación de estrategias tendientes al fortalecimiento de políticas de formación docente. Bolívia, setembro de 2003. Disponível em: <www.oei.es>. Acesso em: 20 maio 2005.

OLIVEIRA, D. A reestruturação do trabalho docente: precarização e flexibilização. Educação \& Sociedade, Campinas, n. 89, p. 1127-1144, 2004.

Educação básica: gestão do trabalho e da pobreza. Petrópolis: Vozes, 2000.

Mudanças na organização e na gestão do trabalho na escola. In: OLIVEIRA, D. A.; ROSAR, M. de F. F. (Orgs.). Política e gestão da educação. Belo Horizonte: Autêntica, 2002. p. 125-143.

OZGA, J. Investigação sobre políticas educacionais: terrenos de contestação. Porto: Porto Editora, 2001.

PURYEAR, J. M. Educação na América Latina: problemas e desafios. Série PREAL DOCUMENTOS, v. 7. Programa de Promoção da Reforma Educativa na América Latina e Caribe. Disponível em: <http//www.cpdoc.fgv.br/projetos/htm/pr_det_and017.htm>. Acesso em: 10 set. 2003.

ROBERTSON, S. L.; DALE, R. Regulação e risco na governação da educação: gestão dos problemas de legitimação e coesão social em educação nos Estados competitivos. Educação, Sociedade \& Cultura. n. 15, p. 117-147, 2001.

SCHULTZ, T. W. 0 capital humano. Rio de Janeiro: Zahar, 1971.

SHIROMA, E. 0.; EVANGELISTA, 0. Profissionalização: da palavra à política. In: PACHECO, J. A.; MOARES, M. C. M. de; EVANGELISTA, 0. Formação de professores: perspectivas educacionais e curriculares. Porto: Porto Editora, 2003. p. 27-45.

Educação para o alívio da pobreza: novo tópico na agenda global. Quaestio. v. 7, n. 2, p. 97-111, 2005.

SHIROMA, E. O. Gerencialismo e liderança: novos motes da gestão educacional. VI Seminário de Pesquisa em Educação da Região Sul. Santa Maria: UFSM; CD-ROM, 2006. 12p.

STOER, S.; ARAÚJO, H. C. Escola e aprendizagem para o trabalho num país da (semi) periferia europeia. 2. ed. Lisboa: IE, 2000.

TORRES, R. M. El laberinto de la "cooperación internacional para la educación" mirado desde América Latina y el Caribe (documento em proceso). 2004. Disponível em: <www.fronesi.org>. Acesso em: 30 maio 2006.

UNESCO. Primera reunión intergubernamental del proyecto regional de educación para América Latina e Caribe. Proyecto regional de educación para América Latina e Caribe. Cuba, novembro de 2002. Disponível em: <http://www.unesco.cl/medios/ biblioteca/documentos/prelac_proyecto_regional_educacion_esp.pdf?menu=/port/prelac/docdig/>.Acesso em:09 mar. 2005.

Recebido em 21.07.06

Aprovado em 13.08.07

Olinda Evangelista, doutora em História da Educação (PUC/SP), pós-doutorado na Universidade do Minho, Portugal, pesquisadora do Grupo de Estudos sobre Política Educacional e Trabalho (GEPETO) - www.gepeto.ced.ufsc.br., pesquisadora do CNPq, é professora do Departamento de Estudos Especializados em Educação, Centro de Ciências da Educação, Universidade Federal de Santa Catarina.

Eneida Oto Shiroma, doutora em Educação (UNICAMP), pós-doutorado na Universidade de Nottingham, Inglaterra, e pesquisadora do GEPETO e do CNPq, é professora do Departamento de Estudos Especializados em Educação, Centro de Ciências da Educação, Universidade Federal de Santa Catarina. 